\title{
Curcumin differentially affects cell cycle and cell death in acute and chronic myeloid leukemia cells
}

\author{
MACARIO MARTÍNEZ-CASTILLO ${ }^{1}$, NICOLAS VILLEGAS-SEPÚLVEDA ${ }^{1}$, MARCO A. MERAZ-RIOS ${ }^{1}$, \\ ARACELI HERNÁNDEZ-ZAVALA ${ }^{2}$, JAIME BERUMEN ${ }^{3,4}$, MATHEW A. COLEMAN $^{5,6}$, \\ LORENA OROZCO $^{7}$ and EMILIO J. CORDOVA ${ }^{7}$ \\ ${ }^{1}$ Department of Molecular Biomedicine, Center of Studies and Advance Research, 07360 Mexico City; \\ ${ }^{2}$ Section of Research and Postgraduate, Superior School of Medicine, National Institute Polytechnique, \\ Plan de San Luis S/N, Miguel Hidalgo, Casco de Santo Tomás, 11350 Mexico City; \\ ${ }^{3}$ Faculty of Medicine, National Autonomous University of Mexico (UNAM), AP, 04510 Mexico City; \\ ${ }^{4}$ Unit of Genomic Medicine, Hospital General, 06720 Mexico City, Mexico; \\ ${ }^{5}$ Lawrence Livermore National Laboratory, Livermore, CA 94550; \\ ${ }^{6}$ Department of Radiation Oncology, University of California Davis, School of Medicine, Davis, CA 95817, USA; \\ ${ }^{7}$ National Institute of Genomic Medicine, Clinic Research, 14610 Mexico City, Mexico
}

Received August 2, 2017; Accepted January 24, 2018

DOI: $10.3892 / \mathrm{ol} .2018 .8112$

\begin{abstract}
Curcumin is a phytochemical with potent antineoplastic properties. The antitumoral effects of curcumin in cells derived from chronic or acute myeloid leukemia have been already described. However, a comparative study of the cytostatic and cytotoxic effects of curcumin on chronic and acute myeloid leukemia cells has not yet been performed. In the present study, the cellular effects of curcumin on cell lines derived from chronic or acute myeloid leukemia were examined. Dose and time-response assays were performed with curcumin on HL-60 and K562 cells. Cell viability was evaluated with trypan blue exclusion test and cell death by flow cytometry using a fluorescent molecular probe. A cell cycle profile was analyzed, and protein markers of cell cycle progression and cell death were investigated. In the present study, the K562 cells showed a higher sensitivity to the cytostatic and cytotoxic effects of curcumin compared with HL-60. In addition, curcumin induced G1 phase arrest in HL-60 cells and G2/M phase arrest in K562 cells. Furthermore, curcuminrelated cell death in HL-60 was associated with the processed forms of caspases- 9 and -3 proteins, whereas in K562 cells, both the processed and the unprocessed forms were present. Accordingly, activity of these caspases was significantly higher in HL-60 cells compared with that in K562. In conclusion,
\end{abstract}

Correspondence to: Dr Emilio J. Cordova, National Institute of Genomic Medicine, Clinic Research, Periférico Sur 4809, Col. Arenal Tepepan C.P., 14610 Mexico City, Mexico

E-mail: ecordova@inmegen.gob.mx

Key words: curcumin, chemoprevention, leukemia, K562, HL-60, cell cycle, apoptosis curcumin elicits different cellular mechanisms in chronic or acute myeloid leukemia cells and the powerful antitumoral effect was more potent in K562 compared with HL-60 cells.

\section{Introduction}

Curcumin is an important bioactive compound derived from the rhizome of the plant Curcuma longa Linn, which has been used in traditional medicine for centuries. This phytochemical has demonstrated potent antineoplastic activities in various animal and cellular models of cancer. For example, curcumin exerts powerful antiproliferative effects in cell lines derived from colon, and lung cancers $(1,2)$. Similarly, curcumin is able to reduce the development of breast, lung, and hepatic tumors in various mouse models $(3,4)$. Importantly, numerous human clinical trials have also demonstrated the safety and efficacy of curcumin as an adjuvant for cancer therapy $(5,6)$.

Curcumin features natural anticancer properties and delivers potent cytostatic and cytotoxic effects against neoplastic cells. Notably, however, curcumin's cytotoxic effects, including cell cycle arrest and cell death, are specific to the genetic background of the tumor-derived cells. For example, curcumin exposure induced a cell cycle arrest in the G1 phase in prostate and breast cancer-derived cell lines $(7,8)$; whereas, it induced a G2/M arrest in glioma and colorectal cancer cells $(9,10)$. Likewise, curcumin exposure is able to promote different mechanisms of cell death depending on the tumor cell type. For example, curcumin treatment of prostate, colon, and lung cancer cells causes apoptosis (11-13), while causing mitotic catastrophe in pancreatic and esophageal tumor-derived cells $(14,15)$. Furthermore, curcumin exposure was related to autophagy in melanoma and hepatocellular carcinoma cell lines $(16,17)$.

In hematological malignancies, previous reports have shown the potential of curcumin to provoke a reduction in 
cellular proliferation and an increase of cell death in cell lines derived from chronic and acute myeloid leukemia (18-22). However, controversial results have been obtained from these studies. For example, Sarkar et al (19) and Zhang et al (20) demonstrated that curcumin induced a cell cycle arrest at the $\mathrm{G} 2 / \mathrm{M}$ phase in the acute myeloid leukemia-derived cell line HL-60; whereas in the same cell line, Liu et al (21) and Chen et al (22) reported a curcumin-related cell cycle arrest in G1 phase. In addition, previous reports showed that treatment of the chronic myeloid leukemia-derived cell line K562 with curcumin promoted apoptosis through the activation of caspases-9 and $-3(23,24)$. Another study found that curcumin activates both apoptosis and autophagy in K562 cells (25).

It is worth noting that a comparative study investigating the different cytotoxic and cytostatic effects of curcumin on cell lines derived from chronic or acute myeloid leukemia cells has not been carried-out. Therefore, in the present study, we compared the cytostatic and cytotoxic effects of curcumin on both K562 and HL-60 cell lines that are derived from chronic and acute myeloid leukemia cells, respectively. Our results illustrate that curcumin activates different mechanisms for cell cycle arrest and cell death in each type of leukemic cells. In HL-60 cells, curcumin caused a cell cycle arrest in G1 and displayed classical apoptosis, involving activation of caspases- 9 and -3 . In contrast, in K562 cells, curcumin induced a $\mathrm{G} 2 / \mathrm{M}$ arrest, followed by a cell death process similar to mitotic catastrophe, with partial activation of caspases-9 and -3 .

\section{Materials and methods}

Cell cultures. The cell lines derived from chronic myeloid leukemia (K562) and from acute promyelocytic leukemia (HL-60) were obtained from the American Type Culture Collection (ATCC; Manassas, VA, USA). Cell cultures were grown in RPMI-1640 medium containing $10 \%$ fetal bovine serum (FBS), $50 \mathrm{U} / \mathrm{ml}$ penicillin, $50 \mu \mathrm{g} / \mathrm{ml}$ streptomycin and $1 \%$ (v/v) non-essential amino acids (Gibco, Grand Island, NY, USA). Additionally, medium for HL-60 cells was supplemented with $2 \mathrm{mM}$ GlutaMAX (Gibco, Grand Island, NY, USA). Cell cultures were maintained in an incubator at $37^{\circ} \mathrm{C}$ with $95 \%$ humidity and $5 \%$ of $\mathrm{CO}_{2}$. Curcumin was purchased from Sigma-Aldrich (St. Louis, MO, USA) and dissolved in dimethyl sulfoxide (DMSO) (Sigma-Aldrich) at $30 \mathrm{mM}$. Stock solution was kept at $-20^{\circ} \mathrm{C}$ and protected from light until use.

Cellular treatment. To compare the cytostatic and cytotoxic effects of curcumin on HL-60 and K562 cell lines, $2.5 \times 10^{5}$ cells $/ \mathrm{ml}$ from each cell line were grown for $24 \mathrm{~h}$, after which they were incubated with $5,10,15,20$ or $30 \mu \mathrm{M}$ of curcumin for $24 \mathrm{~h}$ (dose-response assays) or with $30 \mu \mathrm{M}$ of curcumin for $6,12,18$, or $24 \mathrm{~h}$ (time-response assays). DMSO $0.1 \%(\mathrm{v} / \mathrm{v})$ (curcumin vehicle) treatment for $24 \mathrm{~h}$ was used as a control culture in both cell lines.

Cell viability assays. After incubation with the indicated treatment, cells were washed once with phosphate-buffered saline (PBS; 1X) and the number of viable cells was determined with the trypan blue exclusion test by direct counting of cells on a light microscope Olympus CKX41 (Olympus, Miami, FL,
USA). Results were expressed as a percentage relative to the respective control culture (which was set $=100 \%$ of viability).

Cell death assays. Cell death was measured with the LIVE/DEAD ${ }^{\circledR}$ Fixable Dead Cell Stain Kit (Thermo Fisher Scientific, Inc., Waltham, MA, USA). This method uses red fluorescent reactive dye to stain the cells with damaged membranes. As a positive control of cell death, both cell lines were treated with $40 \mathrm{~mJ} / \mathrm{cm}^{2}$ of UV irradiation for $2 \mathrm{~min}$ in a cross-linker GS Gene linker-UV chamber (Bio-Rad, Hercules, CA, USA) and recovered $24 \mathrm{~h}$ post-irradiation. After the indicated treatments, cells were pelleted, washed with PBS 1X, and stained with $1 \mu \mathrm{l}$ of fluorescent reactive dye from the LIVE/DEAD ${ }^{\circledR}$ Stain Kit. Cell suspensions were protected from light and incubated on ice for $30 \mathrm{~min}$. Data was captured using the FACSCalibur flow cytometer system (Beckman Coulter, San Jose, CA, USA). At least 20,000 events were recorded for each sample. Data analysis was performed with the Summit Software (version 5.1.0.5563; Beckman Coulter).

Cell cycle assays. The K562 and HL-60 cells exposed to dose- and time-response assays, were pelleted, washed with cold-PBS $1 \mathrm{X}$, and fixed overnight at $-20^{\circ} \mathrm{C}$ with $1 \mathrm{ml}$ of ice-cold $70 \%$ ethanol. Pellets were resuspended in $250 \mu \mathrm{l}$ of PBS $1 \mathrm{X}$ and treated with RNAse A $(0.5 \mathrm{mg} / \mathrm{ml})$ for $1 \mathrm{~h}$ at $37^{\circ} \mathrm{C}$. Then, the cell suspensions were incubated on ice with $10 \mu \mathrm{g} / \mathrm{ml}$ of propidium iodide (Sigma-Aldrich) for $30 \mathrm{~min}$ in the dark. DNA content was measured using a FACSCalibur flow cytometer (Beckman Coulter), and cell cycle analysis performed with ModFit LT $^{\mathrm{TM}}$ software (version 4.1; Verity Software House, Topsham, ME., USA). At least 20,000 events were recorded for each sample.

Western blot analysis. To obtain total protein extracts, cell cultures treated with curcumin were collected and lysed with ProteoJET ${ }^{\mathrm{TM}}$ mammalian cell lysis reagent (Fermentas, Waltham, MA, USA), following the manufacturer's instructions. Whole-cell extracts $(30 \mu \mathrm{g})$ were separated by SDS-PAGE, transferred onto a polyvinylidene difluoride (PVDF) membrane (Perkin-Elmer, Boston, MA, USA), blocked with 5\% non-fat milk in TBS-Tween-20 (10 mM Tris- $\mathrm{HCl}, \mathrm{pH} 7.5,150 \mathrm{mM} \mathrm{NaCl}, 0.1 \%$ Tween-20), and incubated overnight at $4^{\circ} \mathrm{C}$ with specific primary antibodies used at a dilution of 1:1,000. Primary antibodies used were rabbit anti-human polyclonal caspase-9, rabbit anti-human polyclonal caspase-3 and rabbit anti-human polyclonal PARP (Cell Signaling Technology, Inc., Boston, MA, USA; cat. nos. 9502, 9662 and 9542, respectively). Additionally, we used a mouse anti-human monoclonal BubR1, goat anti-human polyclonal p-Chk1 (Ser 345), mouse anti-human monoclonal Chk1 (Santa Cruz Biotechnology, Santa Cruz, CA, USA; cat. nos. sc-47744, sc-17922 and sc-8408) and rabbit anti-human monoclonal Securin (GeneTex, Inc., Irvine, CA, USA; cat. no. GTX62173). Membranes were washed twice with TBS-Tween-20 and incubated at room temperature for $90 \mathrm{~min}$ with horseradish peroxidase-conjugated goat anti-mouse or goat anti-rabbit secondary antibodies (Invitrogen, Camarillo, CA, USA; cat. nos. 62-6520 and 65-6120, respectively) at a dilution of 1:5,000. Signals were detected using SuperSignal West Pico Maximum Sensitivity Substrate (Thermo Fisher Scientific, 

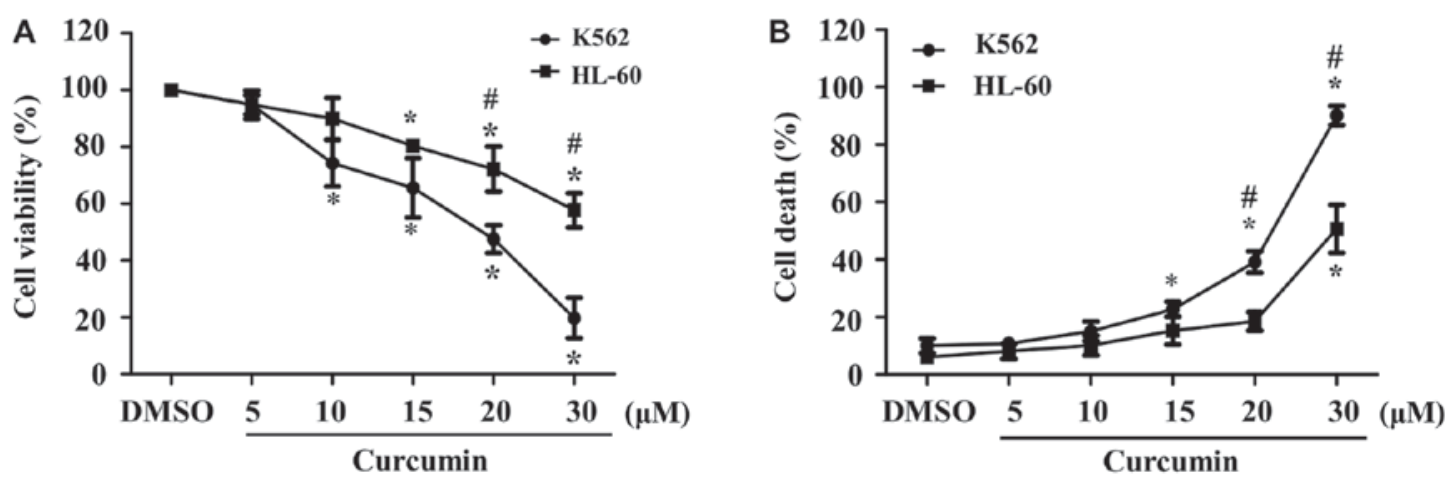

Figure 1. Effects of curcumin on growth and death in K562 and HL-60 cells. (A) Cell viability of K562 and HL-60 cell lines after 24 h of treatment with the indicated concentrations of curcumin. (B) Percentage of cell death in K562 and HL-60 after treatment with various concentrations of curcumin for $24 \mathrm{~h}$ The mean \pm SD are shown. ${ }^{*} \mathrm{P}<0.05$ vs. the respective cell line control (DMSO); ${ }^{*} \mathrm{P}<0.05$ between K562 and HL- 60 cells. Data are representative of at least 3 independent experiments.

Rockford, IL, USA). Membranes were reblotted and incubated with mouse anti-human monoclonal $\beta$-actin (1:500) (US Biological, Swampscott, MA, USA; cat. no. A0760-40) to account for well-to-well variation in loading.

Caspases activity assay. Activity of caspases-9 and -3 was evaluated in cell cultures treated with $30 \mu \mathrm{M}$ of curcumin for $24 \mathrm{~h}$ using specific fluorescence. Briefly, after treatment, cell lines were pelleted, washed, and lysed in lysis buffer $(50 \mathrm{mM}$ HEPES, 5 mM DTT and 1\% Triton X-100) for 30 min. Cellular extracts were clarified by centrifugation at $16,000 \mathrm{x} \mathrm{g}$ for $15 \mathrm{~min}$ at $4^{\circ} \mathrm{C}$, and $100 \mu \mathrm{g}$ of proteins were incubated with $2 \mathrm{ml}$ of caspase specific reaction buffer and $1 \mu \mathrm{M}$ of a fluorescent substrate to either caspase-3 (Ac-DEVD-AMC) or caspase-9 (Ac-LEDH-AFC) from Sigma-Aldrich at $32^{\circ} \mathrm{C}$ for $24 \mathrm{~h}$, in the presence or absence of $2 \mu \mathrm{M}$ of specific inhibitors for caspase-3 (Ac-DEVD-CHO) or caspase-9 (Ac-LEDH-CHO), obtained from Enzo Life Sciences (Lausen, Switzerland). Caspase activity was measured as a function of fluorescence signal produced by the cleavage of synthetic substrate. Activity of caspases was determined by subtracting the fluorescence value obtained in the presence of caspase inhibitor from the value of total fluorescence.

Statistical analysis. Results are expressed as means \pm standard deviation (SD) of at least three independent experiments. Differences between control and curcumin treatments were analyzed by one-way analysis of variance followed by Tukey's multiple comparison test. Differences were considered significant at $\mathrm{P}<0.05$. Statistical analysis was carried out using the GraphPad Prism 5 Software (version 5.01; Hearne Scientific, Pty Ltd., Melbourne, Australia).

\section{Results}

K562 cell line exhibits a higher susceptibility than HL-60 to curcumin effects. To determine the effect of curcumin on cell viability in acute (HL-60) and chronic (K562) myeloid leukemia-derived cell lines, both were treated for $24 \mathrm{~h}$ with increasing doses (5 to $30 \mu \mathrm{M}$ ) of the phytochemical. Although we observed a dose-dependent reduction in cellular viability in both cell lines, the percentage of viable K562 cells decreased to $<80 \%$ at doses as low as $10 \mu \mathrm{M}$, whereas in HL-60 cells, a similar reduction of the percentage of viability was observed until $20 \mu \mathrm{M}$. Moreover, cellular viability at the highest dose of curcumin was significantly lower in K562 than in HL-60 cells (20 vs. 60\%, respectively) (Fig. 1A). These data indicate that the K562 cell line is more sensitive to curcumin than HL-60 cells.

In addition, we evaluated cytotoxic properties of curcumin in K562 and HL-60 cells exposed to different concentrations of the phytochemical for $24 \mathrm{~h}$. As expected, we observed a dose-dependent increase in the percentage of cell death in both cell cultures, which started at lower doses of the phytochemical in K562, in comparison with HL-60 cells (15 vs. $30 \mu \mathrm{M}$, respectively). Similar to cell viability, the percentage of cell death at the highest dose of curcumin was significantly higher in K562 than in HL-60 cells (90 vs. 50\%, respectively) (Fig. 1B).

Curcumin produces different effects on cell cycle progression in K562 and HL-60 cell lines. We next investigated the effect of curcumin on cell cycle progression in K562 and HL-60 cell lines in time-response assays, using $20 \mu \mathrm{M}$ of the phytochemical to avoid the excessively toxic effects observed at higher doses. We found an increase in the percentage of $\mathrm{K} 562$ cells at the $\mathrm{G} 2 / \mathrm{M}$ phase in a time-dependent manner; whereas the HL-60 cell line had a small level of cells accumulated in G1 phase, which may suggest the presence of a G1 arrest (Fig. 2A and B). These observations indicate that HL-60 and K562 cells were affected by curcumin at different points in cell cycle progression.

To further analyze the cytostatic effect of curcumin in K562 and HL-60 cells, we co-incubated cell cultures with curcumin $(20 \mu \mathrm{M})$ and nocodazole $(200 \mathrm{nM})$, an effective inhibitor of microtubule polymerization and a potent inducer of mitotic arrest. In the case of K562 cells, co-incubation of nocodazole with curcumin caused a higher accumulation of cells in G2/M (79.8\%), than those observed in the individual curcumin treatment (44.3\%) (Fig. 2C). On the other hand, HL-60 cultures incubated simultaneously with nocodazole and curcumin showed no significant difference in the number of cells in the $\mathrm{G} 2 / \mathrm{M}$ phase $(21.4 \%)$, in comparison with those treated with curcumin (22.8\%) (Fig. 2D). 
A

K562

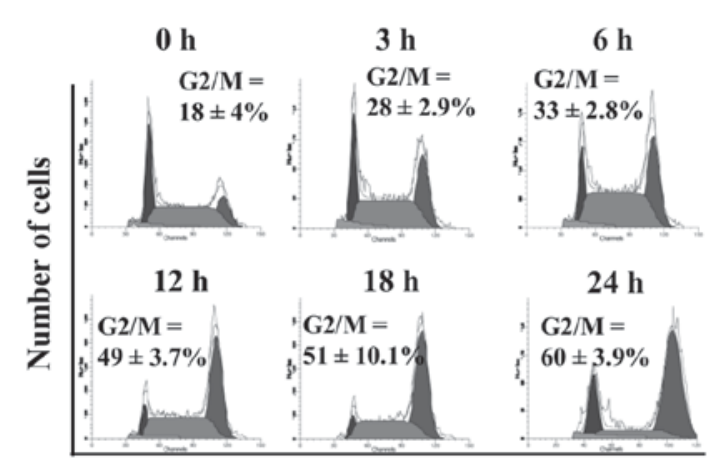

DNA content

C

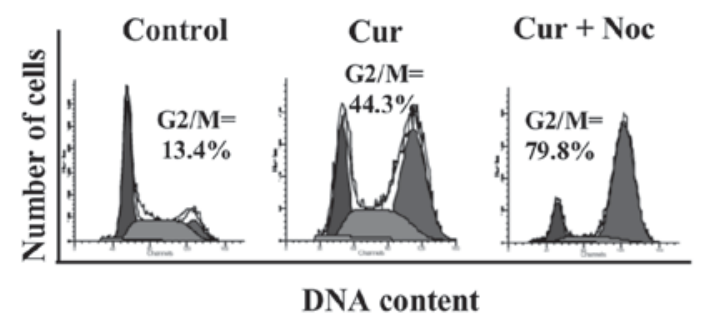

E

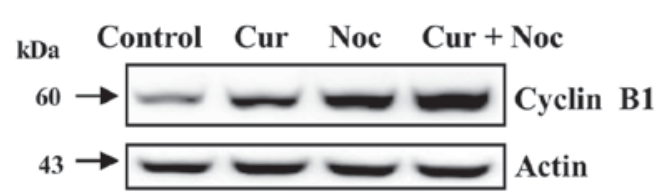

B

HL-60

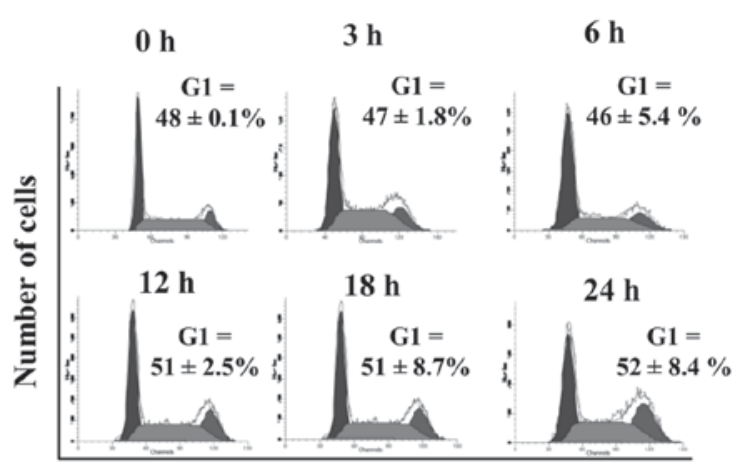

DNA content

D

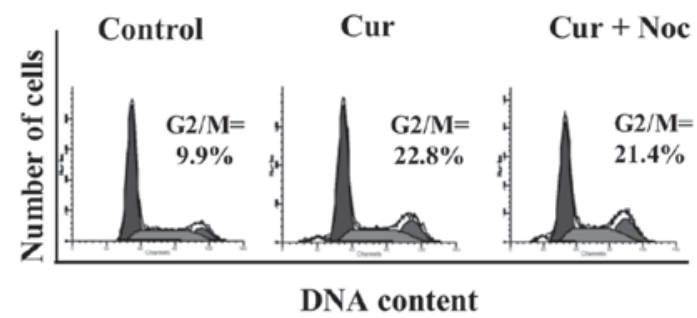

F

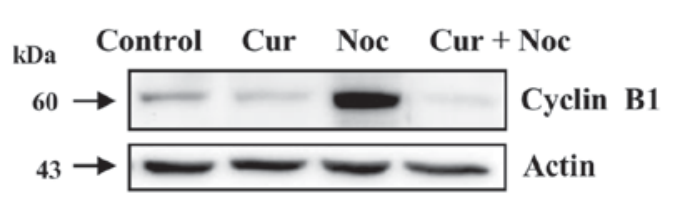

Figure 2. Curcumin differentially alters cell cycle progression in chronic or acute myeloid leukemia cells. (A) K562 and (B) HL-60 cells were treated with curcumin $20 \mu \mathrm{M}$ for different time points. Cells were fixed and stained with propidium iodide for analysis of cell cycle distribution. (C) K562 and (D) HL-60 cells were treated independently with $20 \mu \mathrm{M}$ of curcumin (Cur) or with $20 \mu \mathrm{M}$ of curcumin plus $200 \mathrm{nM}$ of nocodazole (Cur+Noc) by $24 \mathrm{~h}$. Cells were fixed and stained with propidium iodide for analysis of cell cycle distribution. Protein levels of cyclin B1 after the indicated treatment in (E) K562 and (F) HL-60 cells are shown. Actin was used as loading control. Control and time 0 cultures were treated with vehicle (DMSO) for $24 \mathrm{~h}$. Data are representative of at least 3 independent experiments.

We also evaluated the protein levels of cyclin $\mathrm{B} 1$, which is normally a high abundance protein in the G2/M transition phase. In K562 cells, treatment with curcumin or nocodazole alone induced a significant accumulation of cyclin B1, whereas co-incubation produced a synergistic effect (Fig. 2E). In contrast, in HL-60 cells protein levels of cyclin B1 were increased only with the nocodazole treatment (Fig. 2F). Taken together, these data indicate that curcumin is able to induce a cell cycle arrest in both K562 and HL-60 cells, but at different phases of the cell cycle.

Curcumin-induced activation of caspases is defective in $K 562$ but complete in HL-60 cells. Additionally, we analyzed the activation of caspases- 9 and -3 in response to curcumin treatment as markers of apoptotic cell death. Using a curcumin concentration of $30 \mu \mathrm{M}$ in a time-response assay, the low molecular weight protein fragments of the processed forms of caspases- 9 and -3 were observed, as well as the cleavage fragment of PARP, the caspase-3 substrate, in both K562 and HL-60 cells (Fig. 3A and B). However, in the K562 cell line, the unprocessed forms of caspases-9, -3 , and PARP (47, 35 and $116 \mathrm{kDa}$, respectively) were still present up to the end of the incubation time (Fig. 3A; upper band in each panel). In sharp contrast, in HL-60 cells the unprocessed forms of the two caspases, and PARP protein were no longer observable after $18 \mathrm{~h}$ of treatment with curcumin $30 \mu \mathrm{M}$ (Fig. 3B). In accordance with these data, activity of caspase- 9 and -3 after incubation with $30 \mu \mathrm{M}$ of curcumin for $24 \mathrm{~h}$ was significantly lower in K562 as compared to the HL-60 cell line (Fig. 3C). These data suggest that caspases activation is an essential step in curcumin-induced cell death in HL-60 cells, but not necessarily in K562.

Curcumin triggers a defective DNA damage checkpoint at G2 phase in K562 cells. Curcumin is a known inducer of DNA damage in different types of tumoral cells $(26,27)$. Thus, we analyzed in K562 cells, the activation of the DNA damage checkpoints in $\mathrm{G} 2$ and mitosis in response to curcumin, by detecting the phosphorylated status of the checkpoint proteins Chk1, Securin and BubR1. We observed no activation by phosphorylation in Ser-345 of the G2 checkpoint regulator Chk1 during the entire exposure to curcumin (Fig. 4A). In sharp contrast, the level of the phosphorylated and active forms of the mitotic checkpoint regulators Securin and BubR1 increased in a time-dependent manner after curcumin exposure (Fig. 4B). 

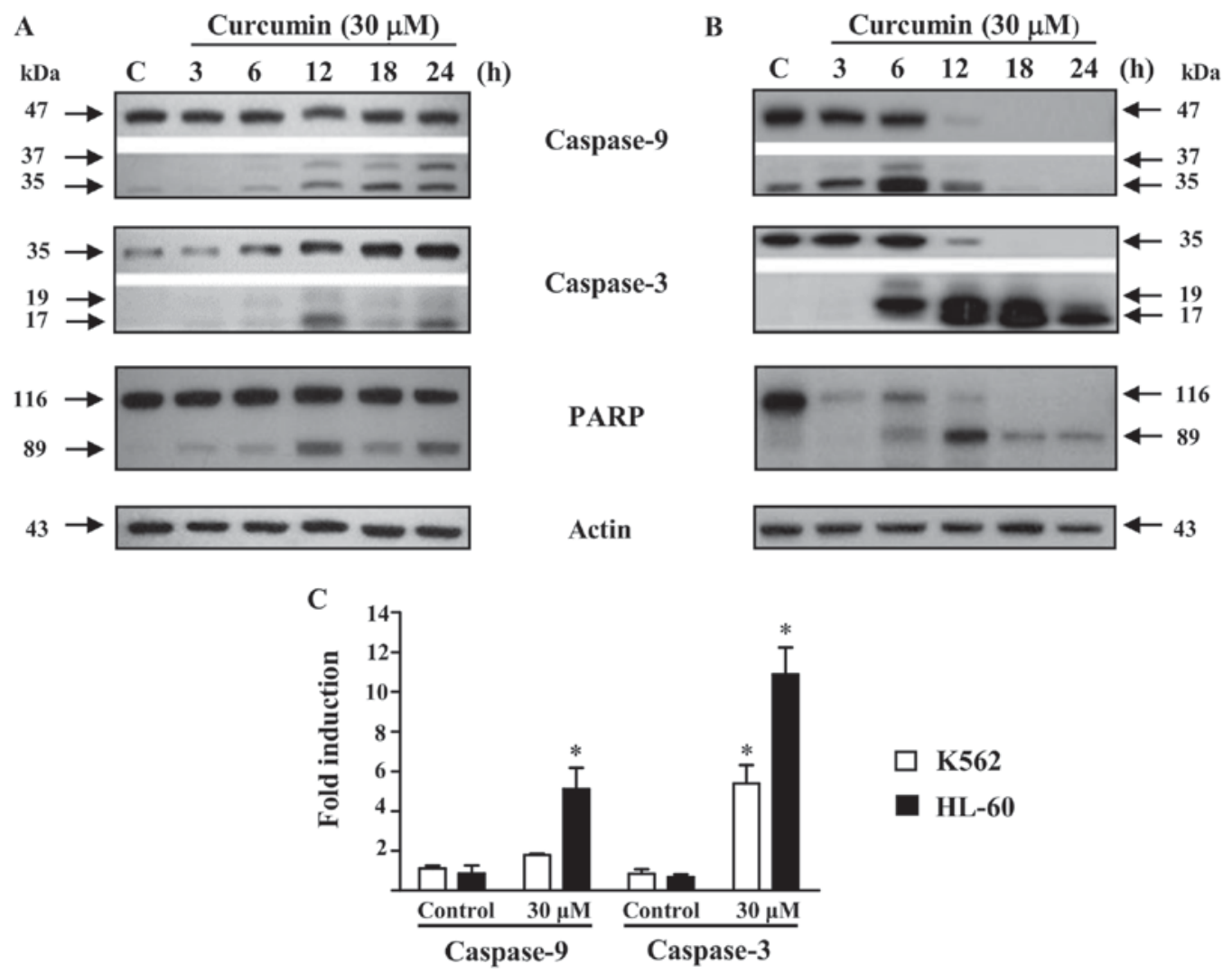

Figure 3. Curcumin induced differential activation of caspases in chronic or acute myeloid leukemia cells. Western blot analysis of caspases and PARP in (A) K562 and (B) HL-60 cells after different times of treatment with $30 \mu \mathrm{M}$ curcumin. Actin protein was utilized as loading control. Control cultures were treated with vehicle (DMSO) for $24 \mathrm{~h}$. $\mathrm{C}=$ Control. Data are representative of at least 3 independent experiments. (C) Cell cultures were treated with $30 \mu \mathrm{M}$ curcumin for $24 \mathrm{~h}$ and activity of caspase- 9 and -3 was evaluated in K562 and HL-60. Values are represented as the mean \pm standard deviation of at least 3 independent experiments. $\mathrm{P}<0.05$ vs. the respective cell line control (DMSO).
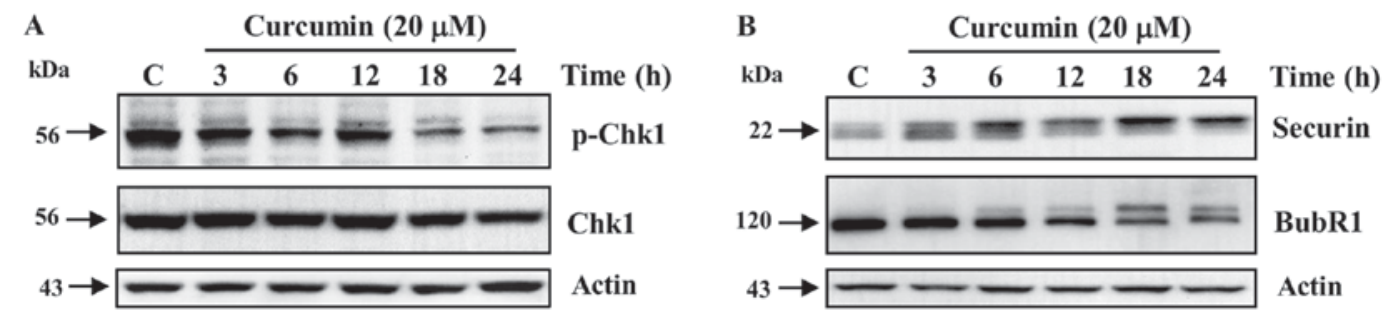

Figure 4. Curcumin exposure promoted a defective DNA damage checkpoint at G2 phase in chronic myeloid leukemia cells. K562 cells were incubated with curcumin $20 \mu \mathrm{M}$ for different time points. (A) Protein levels of total and phosphorylated Chk1 (p-Chk1) after incubation with curcumin. (B) Phosphorylation status of Securin and BubR1 protein in response to curcumin incubation. Actin was used as loading control. Control cultures were treated with vehicle (DMSO) for $24 \mathrm{~h}$. Data are representative of at least 3 independent experiments.

\section{Discussion}

Curcumin is a natural bioactive compound which exerts antiproliferative and pro-apoptotic effects in a wide variety of cellular and animal cancer models. In fact, curcumin is being used as a radio and chemo-sensitizer in different types of cancer (28-30). However, several studies have shown that curcumin elicits different responses at the level of cell cycle regulation and cell death, depending upon the dose, time of exposure, and, perhaps most importantly, the tumor cell type. In this sense, the effect of curcumin on the regulation of cell cycle and in cell lines derived from acute and chronic myeloid leukemia (HL-60 and K562 cell lines, respectively) is highly controversial $(19,25)$. Moreover, the cytostatic effects of this phytochemical on cell lines derived from chronic myeloid leukemia have been poorly studied until now. This highlights the necessity of comparative studies assessing the cytostatic and cytotoxic effects of curcumin in these two types of myeloid leukemia cells.

In the case of the acute myeloid leukemia-derived cell line HL-60, previous reports have demonstrated the capacity of curcumin to induce a cell cycle arrest in G1 phase, followed by caspase-dependent induction of apoptosis $(21,31)$. In addition, an independent study reported that G1 arrest induced by curcumin in HL-60 cells was dependent on the pro-oxidant properties of curcumin (30). In contrast, other studies described a G2/M arrest in HL-60 cells exposed to curcumin $(19,20)$. Our assays, using simultaneous treatment 
with nocodazole and curcumin (mitotic-trap), clearly demonstrated that the phytochemical induced a G1 arrest in the HL-60 cell line. In agreement with our present findings using this mitotic-trap method, curcumin exposure was also shown to induced a G1 arrest in other acute myeloid leukemia-derived cell lines such as MV4-11, KG1a, and Kasumi-1 (32). We have no clear explanation for the discrepancy between our findings and those describing $\mathrm{G} 2 / \mathrm{M}$ arrest $(19,20)$, but it is important to note that the curcumin concentration used in the previous study was lower $(10 \mu \mathrm{M})$ than that used in our present study.

Regarding chronic myeloid leukemia-derived cell line $\mathrm{K} 562$, few studies have analyzed the cytostatic effects of curcumin. However, in agreement with the curcumin-induced $\mathrm{G} 2 / \mathrm{M}$ arrest we observed in the present study, in a mouse lymphoblastoid model overexpressing the BCR-ABL chimeric protein, curcumin exposure also induced a G2/M arrest (33). Notably, arsenic trioxide, a potent pro-oxidant compound used as a therapy in acute myeloid leukemia, also induced a $\mathrm{G} 2 / \mathrm{M}$ arrest in K562 cells, whereas in leukemia-derived cell lines lacking the $B C R-A B L$ fusion gene (e.g. HL-60 and U937) induced a G1 arrest (34). These data indicate that the underlying cellular mechanisms, which are responsible for curcumininduced cell cycle arrest in HL-60 and K562 cells are different, and could be related to the presence of the $B C R-A B L$ fusion.

We also observed differential effects of curcumin on cell death between HL-60 and K562 cells. In accordance with previous reports, we found that HL-60 cells exposed to curcumin showed induction of caspase-dependent apoptosis as a late event. Nevertheless, in the case of K562 cells, we found that curcumin-related cell death occurred at the G2/M transition phase, after a partial activation of caspases-9 and -3 . This may suggest the presence of an alteration in the regulation of apoptosis in K562 cells that avoids full activation of caspases, and thereby triggers an alternative form of cell death. Furthermore, in a recent study, we have demonstrated that curcumin-induced cell death in K562 was produced by mitotic catastrophe (35). In contrast to our data, other studies have reported a curcumin-related activation of caspases-3 and -9, followed by apoptosis in K562 cells $(23,24)$. It is important to note that a previous report demonstrated that curcumin exposure is able to induce apoptosis, through the activation of caspase-9 and -3 , but also to promote autophagy, by the induction of Beclin1 and LC3 proteins (25).

Several previously published experiments highlight the generation of reactive oxygen species and the alteration of tubulin metabolism as the two main mechanisms underlying curcumin effects on regulation of cell cycle progression and cell death (36-38). Our results suggest that HL-60 cells may be able to response to the pro-oxidant properties of curcumin, which induces cell cycle arrest at G1, followed by classical apoptosis, with full activation of caspases. On the other hand, in K562 cells, which may be not proficient at inducing cell cycle arrest at G1 and classical apoptosis, curcumin's effects are likely due to its ability to disrupt tubulin metabolism, which induces a G2/M arrest and cell death with partial activation of caspases. It is worth to mention that in a previous study (35), we demonstrated the phosphorylation of histone H3 in Ser-10 in $\mathrm{K} 562$ cells, after curcumin $(20 \mu \mathrm{M}$ for $24 \mathrm{~h})$ or nocodazole ( $200 \mathrm{nM}$ for $24 \mathrm{~h}$ ) exposure, indicating the arrest of K562 cells in mitosis. Considering that progression from G2 to mitosis is promoted by the dephosphorylation of T14/Y15 at Cdc2 by CDC25C phosphatase, we speculate that in K562 cells, these residues are dephosphorylated in the treatment with curcumin. In order to test this hypothesis, in future studies we will investigate the celular proteins involved in the regulation of cyclin $\mathrm{B} / \mathrm{Cdc} 2$ activity in response to curcumin in chronic myeloid leukemia cells.

Supporting the hypothesis that K562 cells are not able to induce cell cycle arrest in response to curcumin-related DNA damage, we observed a lack of activation of the DNA damage checkpoint protein Chk1 in the presence of this phytochemical, together with the activation by phosphorylation of the mitotic checkpoint proteins BubR1 and Securin. These data suggest that in K562 the DNA damage checkpoint in G2 is not functioning correctly in response to curcumin, allowing cells with DNA damage to progress into mitosis, where the checkpoint machinery arrest the cell cycle. To further understand cellular response to curcumin exposure in both types of leukemia it would be necessary to evaluate the participation of key molecules in DNA damage response and cell cycle regulation. An important limitation of the present study is the absence of experimental data using markers of DNA damage such as phosphorylation of histone $2 \mathrm{AX}(\gamma-\mathrm{H} 2 \mathrm{AX})$.

In summary, these data represent the first side-by-side comparison regarding the effects of curcumin on two leukemic cell lines, K562 and HL-60 cells. Our results clearly demonstrated that curcumin exposure arrest cell cycle at G1 in HL-60 cells and at G2/M in K562 cells. We also observed that the cellular mechanisms underlying curcumin's effects on cell death regulation in chronic and acute myeloid leukemia-derived cell lines were mechanistically distinct. The HL-60 cells appeared to be dependent upon caspase for curcumin-induced cell death, while the K562 cells underwent cell death in a caspase-independent manner. We consider that these data could help to further analyzed the particular alterations in the mechanisms of cell cycle arrest and cell death in each type of leukemia.

\section{Acknowledgements}

The authors would like to thank Dr Jose Luis Cruz-Colin (National Institute of Genomic Medicine, Clinic Research, Mexico City, Mexico) for his valuable technical assistance for cell culture support and Dr Raúl Bonilla Moreno (Department of Molecular Biomedicine, Center of Studies and Advance Research, Mexico City, Mexico) for expert technical assistance. This work was supported by the Consejo Nacional de Ciencia y Tecnología (CONACyT) grants CB-2014-01243587, 128686, CINVESTAV and INMEGEN. Work was also performed under the auspices of the U.S. Department of Energy by Lawrence Livermore National Laboratory under Contract DE-AC52-07NA27344.

\section{References}

1. Shakibaei M, Buhrmann C, Kraehe P, Shayan P, Lueders C and Goel A: Curcumin chemosensitizes 5-fluorouracil resistant MMR-deficient human colon cancer cells in high density cultures. PLoS One 9: e85397, 2014.

2. Fan Z, Duan X, Cai H, Wang L, Li M, Qu J, Li W, Wang Y and Wang J: Curcumin inhibits the invasion of lung cancer cells by modulating the PKC $\alpha /$ Nox-2/ROS/ATF-2/MMP-9 signaling pathway. Oncol Rep 34: 691-698, 2015. 
3. Ferreira LC, Arbab AS, Jardim-Perassi BV, Borin TF, Varma NR, Iskander AS, Shankar A, Ali MM and Zuccari DA: Effect of curcumin on pro-angiogenic factors in the xenograft model of breast cancer. Anticancer Agents Med Chem 15: 1285-1296, 2015.

4. Huang AC, Lin SY, Su CC, Lin SS, Ho CC, Hsia TC, Chiu TH, Yu CS, Ip SW, Lin TP and Chung JG: Effects of curcumin on $N$-bis(2-hydroxypropyl) nitrosamine (DHPN)-induced lung and liver tumorigenesis in BALB/c mice in vivo. In Vivo 22: 781-785, 2008.

5. Carroll RE, Benya RV, Turgeon DK, Vareed S, Neuman M, Rodriguez L, Kakarala M, Carpenter PM, McLaren C, Meyskens FL Jr and Brenner DE: phase IIa clinical trial of curcumin for the prevention of colorectal neoplasia. Cancer Prev Res 4: 354-364, 2011.

6. Epelbaum R, Schaffer M, Vizel B, Badmaev V and Bar-Sela G: Curcumin and gemcitabine in patients with advanced pancreatic cancer. Nutr Cancer 62: 1137-1141, 2010.

7. Sha J, Li J, Wang W, Pan L, Cheng J, Li L, Zhao H and Lin W: Curcumin induces G0/G1 arrest and apoptosis in hormone independent prostate cancer DU-145 cells by down regulating Notch signaling. Biomed Pharmacother 84: 177-184, 2016.

8. Sun SH, Huang HC, Huang C and Lin JK: Cycle arrest and apoptosis in MDA-MB-231/Her2 cells induced by curcumin. Eur J Pharmacol 690: 22-30, 2012.

9. Cheng C, Jiao JT, Qian Y, Guo XY, Huang J, Dai MC, Zhang L, Ding XP, Zong D and Shao JF: Curcumin induces $\mathrm{G}_{2} / \mathrm{M}$ arrest and triggers apoptosis via FoxO1 signaling in U87 human glioma cells. Mol Med Rep 13: 3763-3770, 2016.

10. Lu JJ, Cai YJ and Ding J: Curcumin induces DNA damage and caffeine insensitive cell cycle arrest in colorectal carcinoma HCT116 cells. Mol Cell Biochem 354: 247-252, 2011.

11. Guo H, Xu YM, Ye ZQ, Yu JH and Hu XY: Curcumin induces cell cycle arrest and apoptosis of prostate cancer cells by regulating the expression of IkappaBalpha, c-Jun and androgen receptor. Pharmazie 68: 431-434, 2013.

12. Cao A, Li Q, Yin P, Dong Y, Shi H, Wang L, Ji G, Xie J and Wu D: Curcumin induces apoptosis in human gastric carcinoma AGS cells and colon carcinoma HT-29 cells through mitochondrial dysfunction and endoplasmic reticulum stress. Apoptosis 18 1391-1402, 2013

13. Yao Q, Lin M, Wang Y, Lai Y, Hu J, Fu T, Wang L, Lin S, Chen L and Guo Y: Curcumin induces the apoptosis of A549 cells via oxidative stress and MAPK signaling pathways. Int J Mol Med 36: 1118-1126, 2015.

14. Subramaniam D, Ramalingam S, Linehan DC, Dieckgraefe BK, Postier RG, Houchen CW, Jensen RA and Anant S: RNA binding protein CUGBP2/CELF2 mediates curcumin-induced mitotic catastrophe of pancreatic cancer cells. PLoS One 6: e16958, 2011

15. O'Sullivan-Coyne G, O'Sullivan GC, O'Donovan TR, Piwocka K and McKenna SL: Curcumin induces apoptosis-independent death in oesophageal cancer cells. Br J Cancer 101: 1585-1595, 2009.

16. Zhao G, Han X, Zheng S, Li Z, Sha Y, Ni J, Sun Z, Qiao S and Song $\mathrm{Z}$ : Curcumin induces autophagy, inhibits proliferation and invasion by downregulating AKT/mTOR signaling pathway in human melanoma cells. Oncol Rep 35: 1065-1074, 2016.

17. Tork OM, Khaleel EF and Abdelmaqsoud OM: Altered cell to cell communication, autophagy and mitochondrial dysfunction in a model of hepatocellular carcinoma: Potential protective effects of curcumin and stem cell therapy. Asian Pac J Cancer Prev 16: 8271-8279, 2015.

18. Tan TW, Tsai HR, Lu HF, Lin HL, Tsou MF, Lin YT, Tsai HY, Chen YF and Chung JG: Curcumin-induced cell cycle arrest and apoptosis in human acute promyelocytic leukemia HL-60 cells via MMP changes and caspase-3 activation. Anticancer Res 26: 4361-4371, 2006.

19. Sarkar R, Mukherjee A, Mukherjee S, Biswas R, Biswas J and Roy M: Curcumin augments the efficacy of antitumor drugs used in leukemia by modulation of heat shock proteins via HDAC6 J Environ Pathol Toxicol Oncol 33: 247-263, 2014.

20. Zhang JR, Lu F, Lu T, Dong WH, Li P, Liu N, Ma DX and Ji CY: Inactivation of FoxM1 transcription factor contributes to curcumin-induced inhibition of survival, angiogenesis, and chemosensitivity in acute myeloid leukemia cells. J Mol Med 92: $1319-1330,2014$
21. Liu Y, Chang RL, Cui XX, Newmark HL and Conney AH Synergistic effects of curcumin on all-trans retinoic acid- and 1 alpha,25-dihydroxyvitamin D3-induced differentiation in human promyelocytic leukemia HL-60 cells. Oncol Res 9: 19-29, 1997.

22. Chen J, Wang G, Wang L, Kang $\mathbf{J}$ and Wang J: Curcumin p38-dependently enhances the anticancer activity of valproic acid in human leukemia cells. Eur J Pharm Sci 41: 210-218, 2010

23. Duvoix A, Morceau F, Schnekenburger M, Delhalle S, Galteau MM, Dicato M and Diederich M. Curcumin-induced cell death in two leukemia cell lines: K562 and Jurkat. Ann N Y Acad Sci 1010: 389-392, 2003.

24. Chakraborty S, Ghosh U, Bhattacharyya NP, Bhattacharya RK and Roy M: Inhibition of telomerase activity and induction of apoptosis by curcumin in K-562 cells. Mutat Res 596: 81-90, 2006.

25. Jia YL, Li J, Qin ZH and Liang ZQ: Autophagic and apoptotic mechanisms of curcumin-induced death in K562 cells. J Asian Nat Prod Res 11: 918-928, 2009.

26. Jiang AJ, Jiang G, Li LT and Zheng JN: Curcumin induces apoptosis through mitochondrial pathway and caspases activation in human melanoma cells. Mol Biol Rep 42: 267-275, 2015.

27. Blakemore LM, Boes C, Cordell R and Manson MM: Curcumin-induced mitotic arrest is characterized by spindle abnormalities, defects in chromosomal congression and DNA damage. Carcinogenesis 34: 351-360, 2013.

28. Mathur A, Abd Elmageed ZY, Liu X, Kostochka ML, Zhang H, Abdel-Mageed AB and Mondal D: Subverting ER-stress towards apoptosis by nelfinavir and curcumin coexposure augments docetaxel efficacy in castration resistant prostate cancer cells. PLoS One 9: e103109, 2014.

29. Zeng Y, Weng G, Fan J, Li Z, Wu J, Li Y, Zheng R, Xia P and Guo K: Curcumin reduces the expression of survivin, leading to enhancement of arsenic trioxide induced apoptosis in myelodysplastic syndrome and leukemia stem-like cells. Oncol Rep 36: 1233-1242, 2016

30. Chen J, Wanming D, Zhang D, Liu Q and Kang J: Water-soluble antioxidants improve the antioxidant and anticancer activity of low concentrations of curcumin in human leukemia cells. Pharmazie 60: 57-61, 2005.

31. Yu J, Peng Y, Wu LC, Xie Z, Deng Y, Hughes T, He S, Mo X, Chiu M, Wang QE, et al: Curcumin down-regulates DNA methyltransferase 1 and plays an anti-leukemic role in acute myeloid leukemia. PLoS One 8: e55934, 2013.

32. Rao J, Xu DR, Zheng FM, Long ZJ, Huang SS, Wu X, Zhou WH, Huang RW and Liu Q: Curcumin reduces expression of Bcl-2, leading to apoptosis in daunorubicin-insensitive $\mathrm{CD} 34^{+}$acute myeloid leukemia cell lines and primary sorted $\mathrm{CD} 34^{+}$acute myeloid leukemia cells. J Transl Med 9: 71, 2011.

33. Wolanin K, Magalska A, Mosieniak G, Klinger R, McKenna S, Vejda S, Sikora E and Piwocka K: Curcumin affects components of the chromosomal passenger complex and induces mitotic catastrophe in apoptosis-resistant Bcr-Abl-expressing cells. Mol Cancer Res 4: 457-469, 2006.

34. Sánchez Y, Simón GP, Calviño E, de Blas E and Aller P: Curcumin stimulates reactive oxygen species production and potentiates apoptosis induction by the antitumor drugs arsenic trioxide and lonidamine in human myeloid leukemia cell lines. J Pharmacol Exp Ther 335: 114-123, 2010.

35. Martinez-Castillo M, Bonilla-Moreno R, Aleman-Lazarini L, Meraz-Rios MA, Orozco L, Cedillo-Barron L, Cordova EJ and Villegas-Sepulveda N: A subpopulation of the K562 cells are killed by curcumin treatment after $\mathrm{G} 2 / \mathrm{M}$ arrest and mitotic catastrophe. PLoS One 11: e0165971, 2016.

36. Qadir MI, Naqvi ST and Muhammad SA: Curcumin: A polyphenol with molecular targets for cancer control. Asian Pac J Cancer Prev 17: 2735-2739, 2016.

37. Chakraborti S, Das L, Kapoor N, Das A, Dwivedi V, Poddar A, Chakraborti G, Janik M, Basu G, Panda D et al: Curcumin recognizes a unique binding site of tubulin. J Med Chem 54: 6183-6196, 2011.

38. Jackson SJ, Murphy LL, Venema RC, Singletary KW and Young AJ: Curcumin binds tubulin, induces mitotic catastrophe, and impedes normal endothelial cell proliferation. Food Chem Toxicol 60: 431-438, 2013. 